NASA

Technical Memorandum 105646

AIAA-92-4034
AVSCOM

Technical Report 92-C-016

\title{
Transonic Turbine Blade \\ Cascade Testing Facility
}

Vincent G. Verhoff and William P. Camperchioli

Lewis Research Center

Cleveland, Ohio

and

Isaac Lopez

Propulsion Directorate

U.S. Army Aviation Systems Command

Lewis Research Center

Cleveland, Ohio

Prepared for the

17th Aerospace Ground Testing Conference

sponsored by the American Institute of Aeronautics and Astronautics

Nashville, Tennessee, July 6-8, 1992 


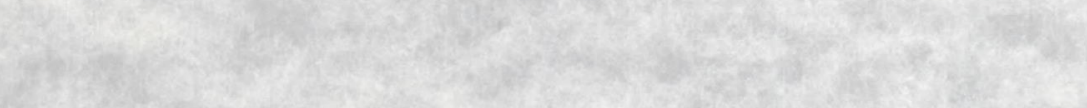
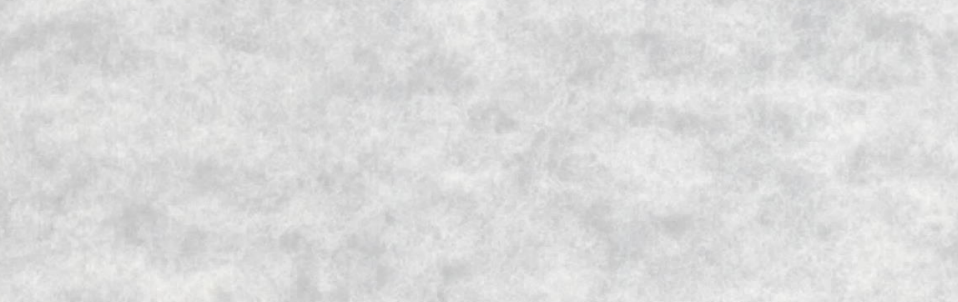

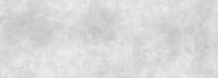

$3+2 x^{2}+x^{2}+3$ 


\title{
TRANSONIC TURBINE BLADE CASCADE TESTING FACILITY
}

\author{
Vincent G. Verhoff and William P. Camperchioli \\ National Aeronautics and Space Administration \\ Lewis Research Center \\ Cleveland, Ohio 44135 \\ and \\ Issac Lopez \\ Propulsion Directorate \\ U.S. Army Aviation Systems Command \\ Lewis Research Center \\ Cleveland, Ohio 44135
}

\begin{abstract}
$\underline{\text { Abstract }}$
NASA Lewis Research Center has designed and constructed a new state-of-the-art test facility. This facility, the Transonic Turbine Blade Cascade, is used to evaluate the aerodynamics and heat transfer characteristics of blade geometries for future turbine applications.

The facility's capabilities make it unique: no other facility of its kind can combine the high degree of airflow turning, infinitely adjustable incidence angle, and high transonic flow rates. The facility air supply and exhaust pressures are controllable to 16.5 and 2 psia, respectively. The inlet air temperatures are at ambient conditions. The facility is equipped with a programmable logic controller with a capacity of 128 input/output channels. The data acquisition system is capable of scanning up to 1750 channels per sec.

This paper discusses in detail the capabilities of the facility, overall facility design, instrumentation used in the facility, and the data acquisition system. Actual research data is not discussed.
\end{abstract}

\section{$\underline{\text { Introduction }}$}

Future turbines will be required to endure and effectively utilize elevated inlet temperatures. Current blade geometries will change significantly to accommodate these higher inlet temperatures.
New blade geometries are required to withstand increased incident kinetic energies and heat loads. NASA Lewis Research Center has designed and constructed a new test facility to evaluate the aerodynamic and heat transfer characteristics of future turbine blade geometries.

The Transonic Turbine Blade Cascade (TTBC) testing facility is used to test advanced turbine blade geometries at high transonic Mach numbers. The transonic flow field database will be beneficial to accurately predict aerothermodynamics for code validation.

The TTBC was designed on a large scale so that detailed measurements could be made easily and accurately. The TTBC has a rectangular cross section that encloses 10 airfoils, resulting in 11 airflow passages. The facility's capabilities make it unique: no other facility of its kind can combine the high degree of airflow turning, infinitely adjustable incidence angle, and high transonic flow rates. Also, the facility can be operated with only two people: one to operate the facility, and another to operate the data acquisition system.

Figure 1 shows photographs of the facility, and Figs. 2 to 4 show graphic representations of the facility. The TTBC control room is shown in Fig. 5. The facility operator's instrumentation and controls are shown in Fig. 6, and the data acquisition system is shown in Fig. 7. 


\section{$\underline{\text { Facility Airflow }}$}

A schematic of the air system of the TTBC is illustrated in Fig. 8. Air is supplied from the NASA Lewis 40-psig combustion air system. Before the air enters the TTBC facility, it is filtered by a $10-\mu \mathrm{m}$ air filter to ensure air purity. A flow-limiting orifice is located on the outlet side of the air filter. This flow-limiting orifice restricts the flow rate to $55 \mathrm{lb}$ per sec with 40 -psig air supply pressure. This safety feature protects the facility from overpressurizing above 22 psia at the plenum chamber. The flow orifice, which determines airflow rate, is downstream of the flowlimiting orifice. After passing through the flow orifice, the flow is regulated and controlled by the inlet control valves. The main inlet control valve is a 30 -in. electric motor-driven butterfly valve operated by toggle controls. The inlet bypass valve is a 10 -in. pneumatic-operated butterfly valve. The inlet bypass valve can be manually or automatically controlled by a feedback controller. A relief valve is located downstream of the control valves and is set to 17 psia. The flow then enters a 108-in.-diam, acoustically lined, plenum chamber. A cross-sectioned illustration of the TTBC facility is shown in Fig. 3. The airflow is conditioned twice, once in the plenum chamber and then in the flow-conditioning section. The flow first passes through a series of flow-conditioning screens in the plenum chamber and then through the plenum bellmouth at the rear of the plenum chamber. Before the flow enters the flowconditioning section, it travels through the transition section. The transition section goes from a 108 -in.-diam cross section to a 48 - by 72 -in. rectangular cross section. The flow then enters the flow-conditioning section where it journeys through a honeycomb and mesh screen section. These sections were designed for ease of replacement. The flow enters the test section after passing through the 48- to 6-in. contraction section. The test section is designed for airfoils with a span of 6 in. In the test section, boundary layers can be removed by the adjustable boundary layer bleed system. Airflow is diffused in the exhaust sections after traveling through the test section. The exhaust travels through a 30 -in. pipe, then into a 48-in.-diam pipe. The exhaust is adjustable and controlled by the main and bypass exhaust control valves. The main exhaust control valve is a 48 -in. electric motor-driven butterfly valve operated by toggle controls. The exhaust bypass valve is a 10 -in. pneumatically operated butterfly valve. The flow is then exhausted into a 2-psia, 150-lb-per-sec altitude exhaust air system after passing through the exhaust isolation valve.

\section{$\underline{\text { Facility Capabilities }}$}

The present configuration for the TTBC incorporates 10 airfoils with 11 airflow passages. The mean airfoil design entailed $132.25^{\circ}$ of flow turning at $0^{\circ}$ of incidence. The incidence angle is infinitely adjustable between -30 and $+15^{\circ}$ with respect to the mean airfoil design. An incidence of $-30^{\circ}$ allows the most axial flow while $a+15^{\circ}$ incidence allows the least axial flow. The cascade was designed for an inlet Mach number of 0.39 and an exit Mach number of 1.3. Future airfoils could have different degrees of airfoil flow turning although the total allowable incident angle range would still be limited to $45^{\circ}$.

The design of the TTBC incorporated flexibility for future flow and airfoil requirements. The inlet airflow is conditioned by honeycomb and screen sections in the flow-conditioning section as shown in Fig. 3. The flow-conditioning sections can be interchanged, removed, or added to obtain the desired flow-conditioning. Incidence angle is achieved through the manual rotation of a large disk (Fig. 4). The airfoils, inlet boards, and boundary bleeds are attached to and interposed between these disks. The inlet airflow remains constant in a horizontal plane as it enters the test section. The airfoil angle of attack is achieved by rotating the disk to the desired incidence angle.

The inlet boards are attached to the rotating disk. These inlets are adjusted to be parallel with each other and the inlet airflow. The inlet boards are also designed to ensure that the inlet board bellmouths are perpendicular to each other.

The test section sidewall boundary layer is removed by a boundary layer bleed manifold system, which is linked into the facility's altitude exhaust. A representation of this system is shown in Fig. 9. The boundary layer bleed scoop is 
removable and replaceable with other boundary layer bleed scoops that vary in cross-sectional area. This design facet allows flexibility by changing the boundary layer bleed opening. If no boundary layer bleed is desired, a boundary layer bleed scoop is installed and covers this entire opening. The sidewall boundary layer bleed is adjustable using 30 hand valves ( 15 per side). The outlets of these hand valves are connected to a central manifold on each test section side. Each manifold flow rate is monitored using a standard line orifice plate. The boundary layer bleed manifold's lines are joined, and flow rate is controlled by a 10-in., pneumatically operated butterfly valve.

\section{$\underline{\text { Data Systems }}$}

Research data is acquired by using a distributed data acquisition system that allows the facility computer hardware to scan up to 1750 channels per sec. The existing computer hardware in the facility allows up to 256 analog channels and approximately 1500 other channels to be scanned. Among the analog channels are thermocouples, pressure transducers, and rotating disk angle positions. Among the other channels input to the facility computer are the actuator positions and pressures which are read from an electronically scanned pressure system.

All temperatures are measured with thermocouples. The thermocouple alloy lead wires are connected to copper wires at an isothermal reference junction block. A platinum resistance temperature detector is embedded in the block and used to measure its temperature. Although all existing thermocouples in the facility are type E, these reference blocks will accept any type thermocouple. The facility is equipped with one isothermal reference junction block, yielding a facility capacity of 48 thermocouples.

The inlet boards and rotating disk angles are measured with an electronic angle readout system. There is a total of six angle transducers, two on each inlet board and two on the rotating disk. Each angle transducer has two readouts, one in the test cell on the rig and one in the control room.
The angles are also recorded on analog channels by the facility computer.

Analog channels are also used to record pressures measured by discrete pressure transducers. Among these are the inlet and exhaust header pressures; the reference, check, and control pressures for the electronically scanned pressure system; and other facility monitoring pressures.

Probe actuators are controlled by a probe actuator control system (PACS). Figure 10 shows a block diagram of the system. The current system consists of 3-axis control, but is expandable up to 64 axes. The system is controlled by a dedicated host computer that not only controls the motions of all axes, but also transfers data to the facility computer. The actuators consist of 25000 steps per revolution stepping motors for drive power and 2000 line optical encoders for position indication. The PACS system is equipped with automatic nulling capabilities for pressure probes and is easily programmed for cyclic data probe surveys.

\section{Pressure System}

The electronically scanned pressure (ESP) system is used to measure a large quantity of pressure data. The existing system in the facility contains 25 pressure modules, each containing 32 pressure transducers, yielding a total of 800 individual pressure channels. The system is easily expandable to 1024 pressure channels with the addition of pressure modules. The existing pressure modules have a range of \pm 15 psid. Atmosphere is currently being used as the reference pressure, yielding a system pressure range of 0 to 30 psia. The overall system accuracy is 0.1 percent full scale.

A block diagram of the pressure system is shown in Fig. 11. The pressure system consists of four main components: the pressure system control computer, the data acquisition and control unit (DACU), the pressure calibrate unit (PCU), and the pressure modules. 
The pressure system control computer is the link between the pressure system and the facility computer. The control computer receives multiplexed data from the pressure system, performs numerical analysis, and packages the data before sending it to the facility computer. The control computer also acts as the master for the pressure system.

The data acquisition and control unit (DACU) is the link between the control computer and the pressure calibrate unit and pressure modules. The DACU addresses the pressure modules, acquires the pressure signals, and multiplexes the data before sending it to the control computer. The DACU also gives the calibration instructions to the pressure calibrate unit (PCU) upon command from the control computer.

The pressure calibrate unit (PCU) performs online calibration of the pressure modules. On command, the PCU will seal off the pressures being applied to the pressure modules and apply a three-pressure calibration to the modules. The calibration pressures can be set by the user, but should evenly span the desired pressure range. The calibration pressures are measured by the PCU through high accuracy quartz pressure transducers. The millivolt signals from each pressure channel are compared to the calibration pressures, and a characteristic equation is generated for each pressure channel.

The frequency of calibrations is user definable; typically, the system is calibrated online every $20 \mathrm{~min}$. A calibration of the pressure modules can be forced anytime, using the control computer keyboard or a dedicated push button.

\section{$\underline{\text { Facility Data Acquisition }}$}

The facility data system provides real-time data acquisition, display, and control of the experiment. ${ }^{1}$ A block diagram of the system is shown in Fig. 12. The data system can provide data acquisition from a variety of devices, including analog voltage inputs, analog measurements from temperatures and pressures, inputs from the electronically scanned pressure system, and position inputs from the probe actuator control system.
The data are stored locally in the test facility and are sent to a central computer for storage and post-run processing. This system can easily be reconfigured for secure data testing.

The data are displayed in real-time to theuser by two color, alphanumeric CRT's, one color graphics CRT, and three 40-character, alphanumeric, individual digital displays (IDD's). The data can be displayed in either raw counts, millivolts, or engineering units. The conversion from millivolts to engineering units is defined for each channel or block of channels by the user. Several standard conversion rules, such as thermocouple conversions, are available. The user may also specify several unique pages of data to be displayed on the CRT's. The data may be displayed in any fashion on these display pages. The various display pages are accessed through a dedicated entry panel, allowing each CRT to display any page anytime. The update rate for the CRT's and IDD's is once per sec.

Online calculations may also be performed and displayed by the data system. Typical online calculations include airflow rates and averaging of multiple data points. The system can code out bad or unused data channels or force these channels to a fixed value. This feature is helpful in maintaining meaningful calculations or averages in a sensor failure.

Limit checking is also performed on userspecified channels. The data system checks all channels every scan for limit violations. If a limit violation occurs, that channel will be displayed in reverse video on the CRT's. In addition, output contact closures can be triggered upon limit violation for use in alarms and shutdowns.

\section{$\underline{\text { Conclusions }}$}

The Transonic Turbine Blade Cascade testing facility has been operational since April 1991.

Thus far, research data results have been excellent. The facilty's data acquisition and operating systems perform well. The overall versatility and design of this facility will prove to be an asset for years to come. 


\section{Reference}

1. Fronek, D.L., Setter, R.N., Blumenthal,

P.Z., and Smally, R.R., "A Distributed

Data Aquisition System for Aeronautics

Test Facilities," NASA-TM-88961, 1987.

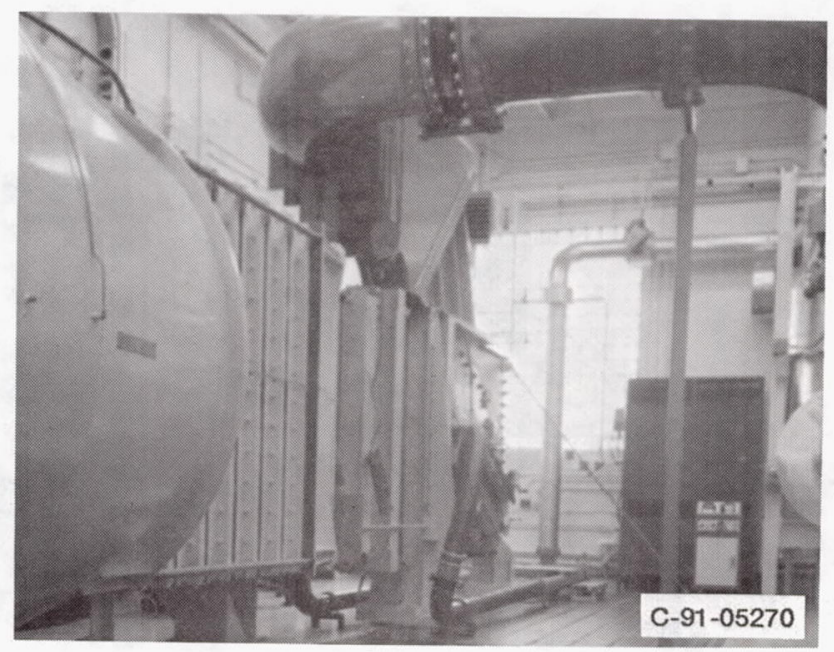

(a) Upstream view.

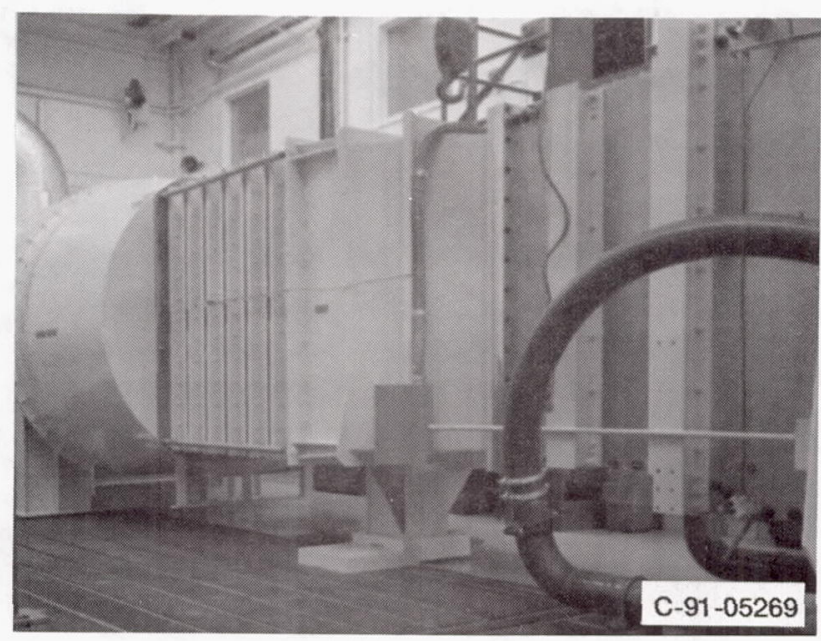

(b) Downstream view.

Fig. 1. Transonic turbine blade cascade testing facility. 


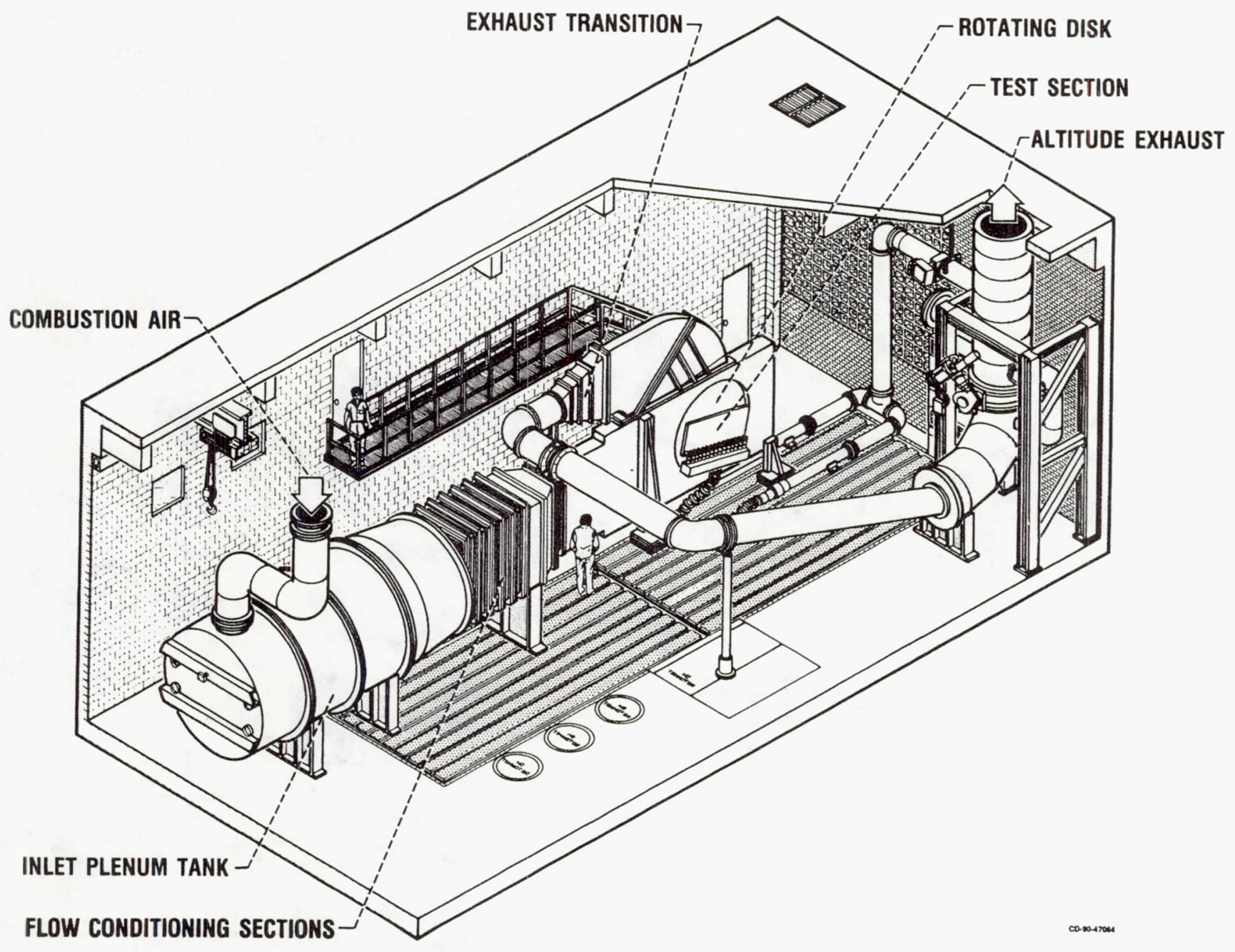

Fig. 2. Transonic Turbine Blade Cascade testing facility. 


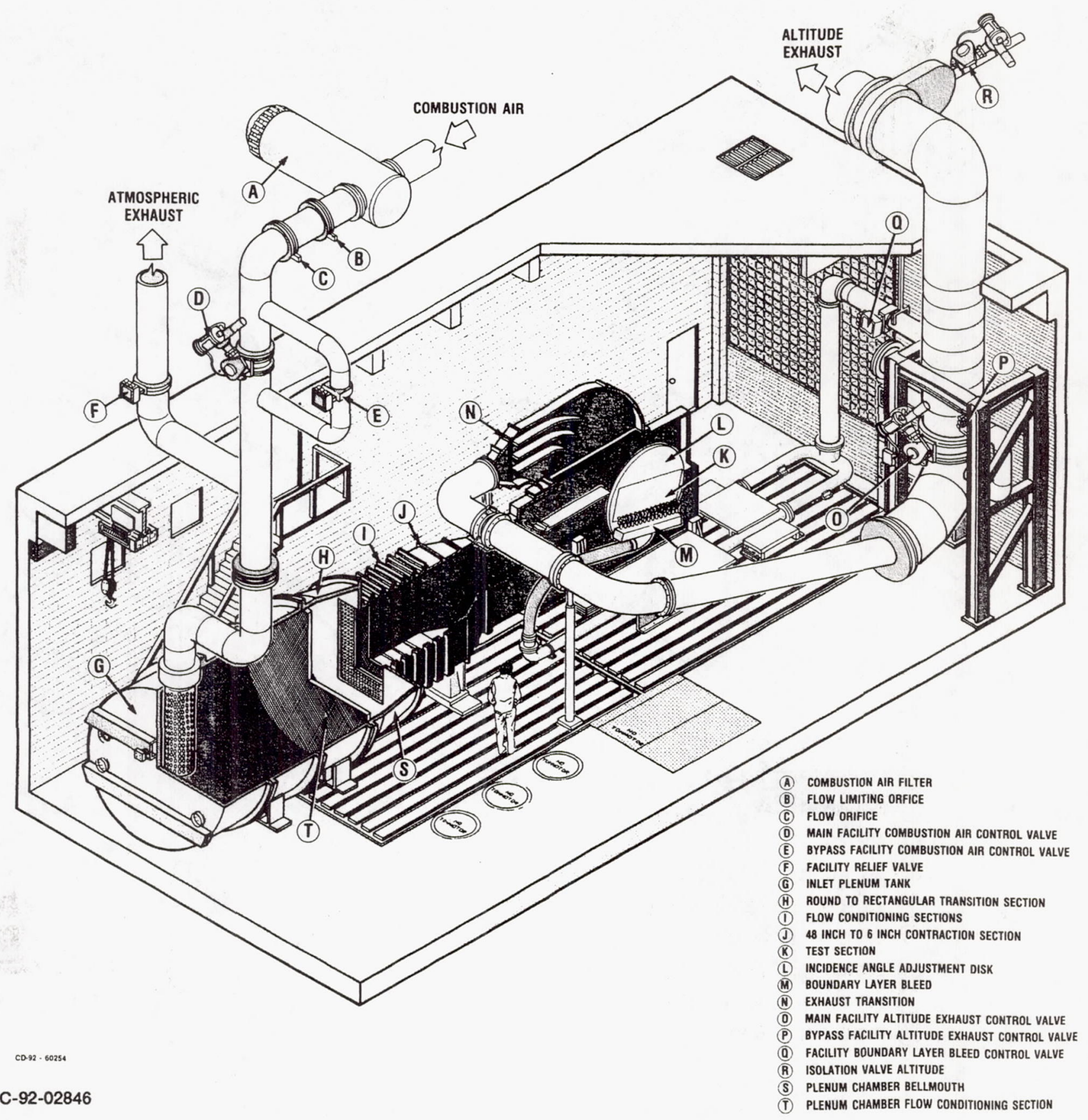

Fig. 3. Transonic Turbine Blade Cascade cross section. 


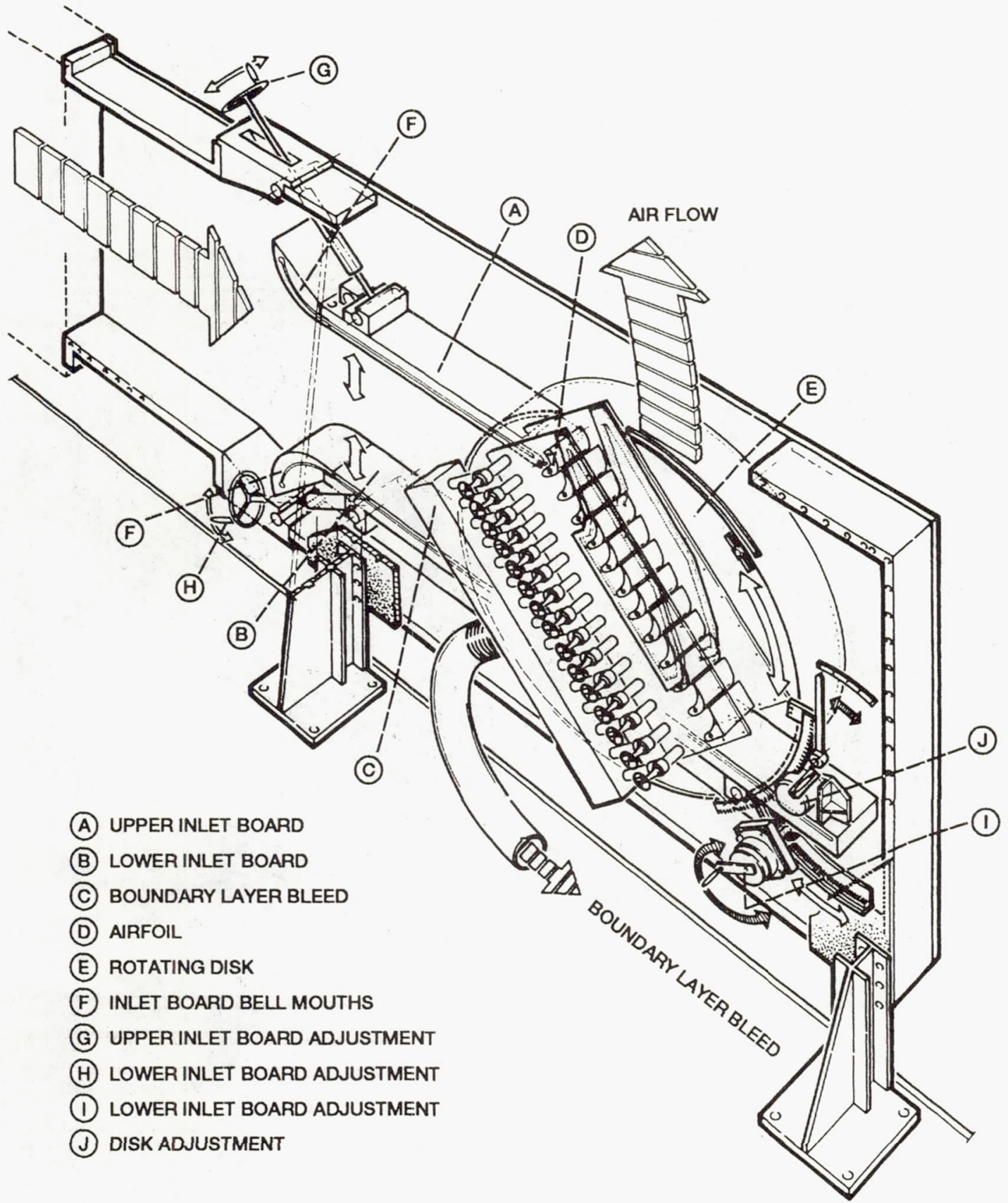

Fig. 4. Transonic Turbine Blade Cascade test section cross section. 


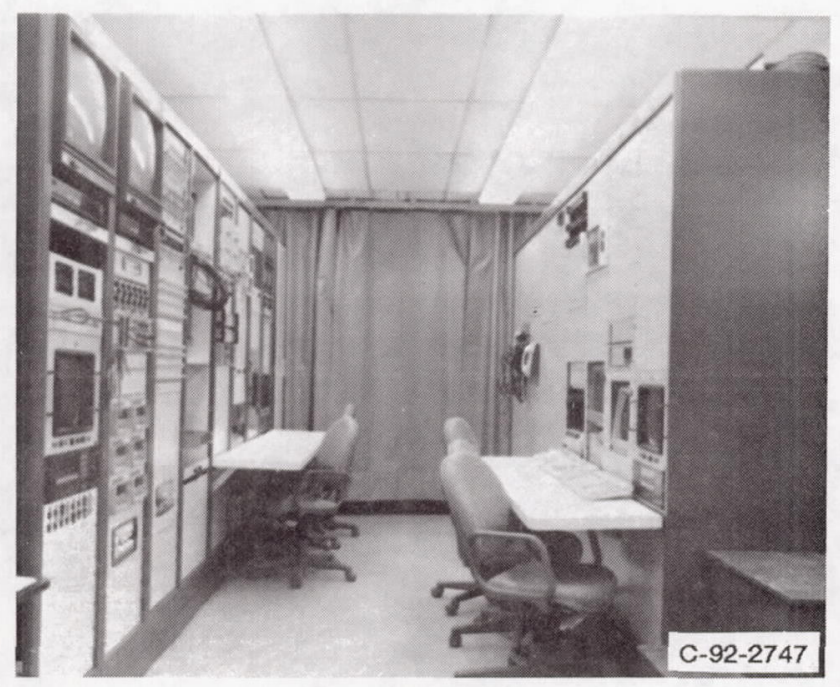

Fig. 5. Transonic turbine blade cascade control room.

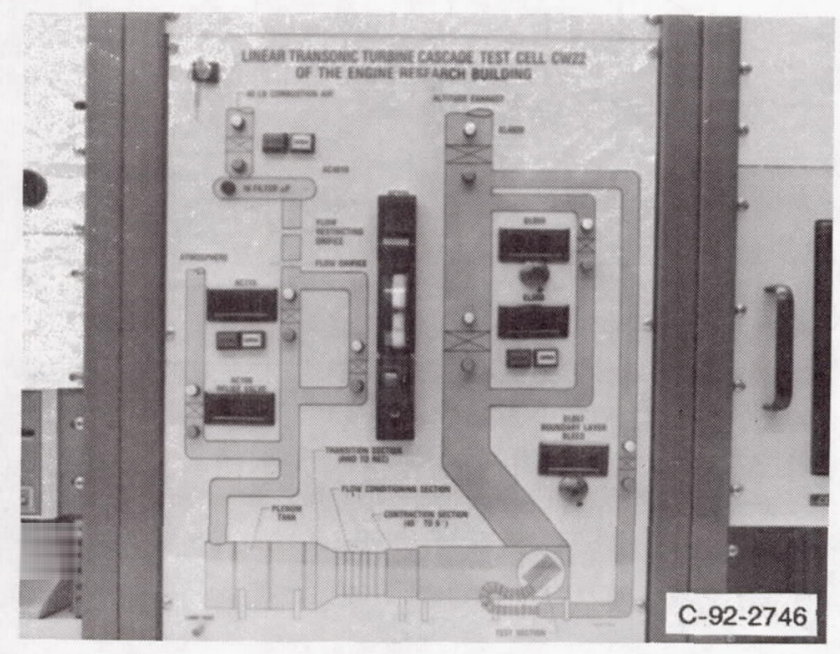

(a) Operator's valve controls.

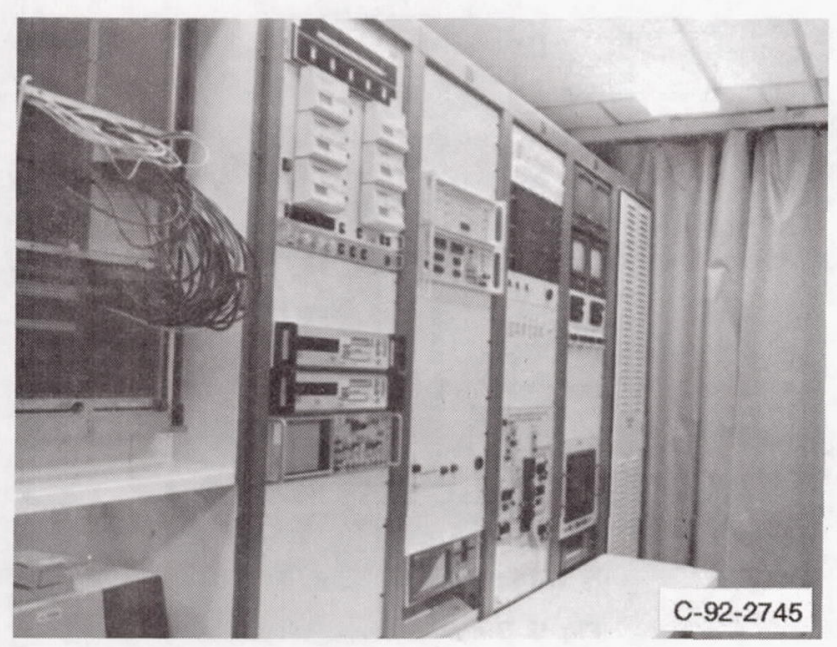

(b) Operator's instrumentation.

Fig. 6. Operator's instrumentation and controls.

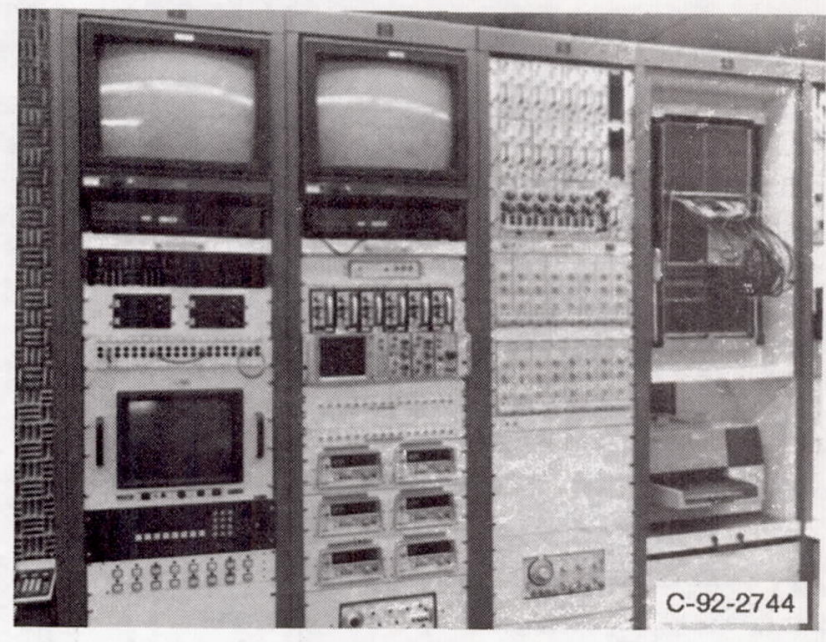

(a) Research instrumentation.

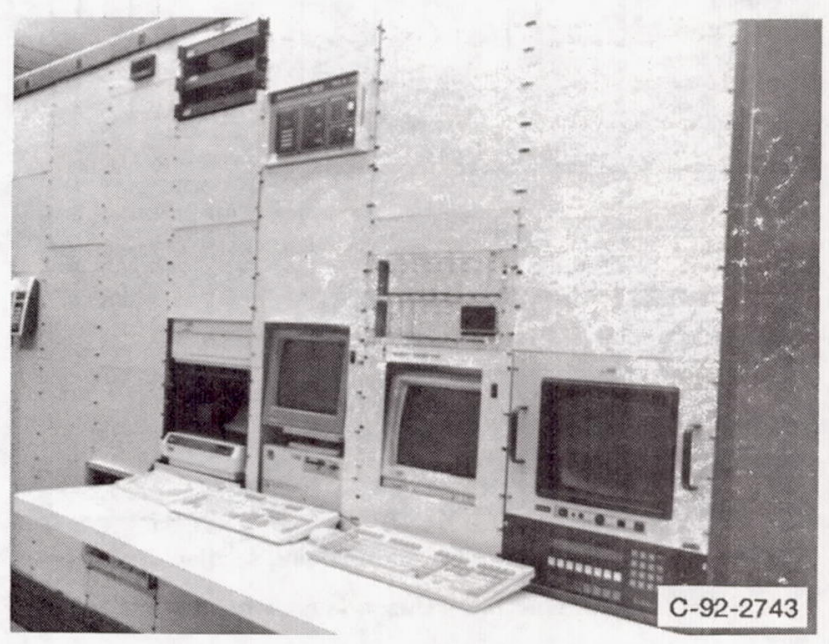

(b) Data acquisition controls.

Fig. 7. Facility data acquisition system. 
40 PSIG

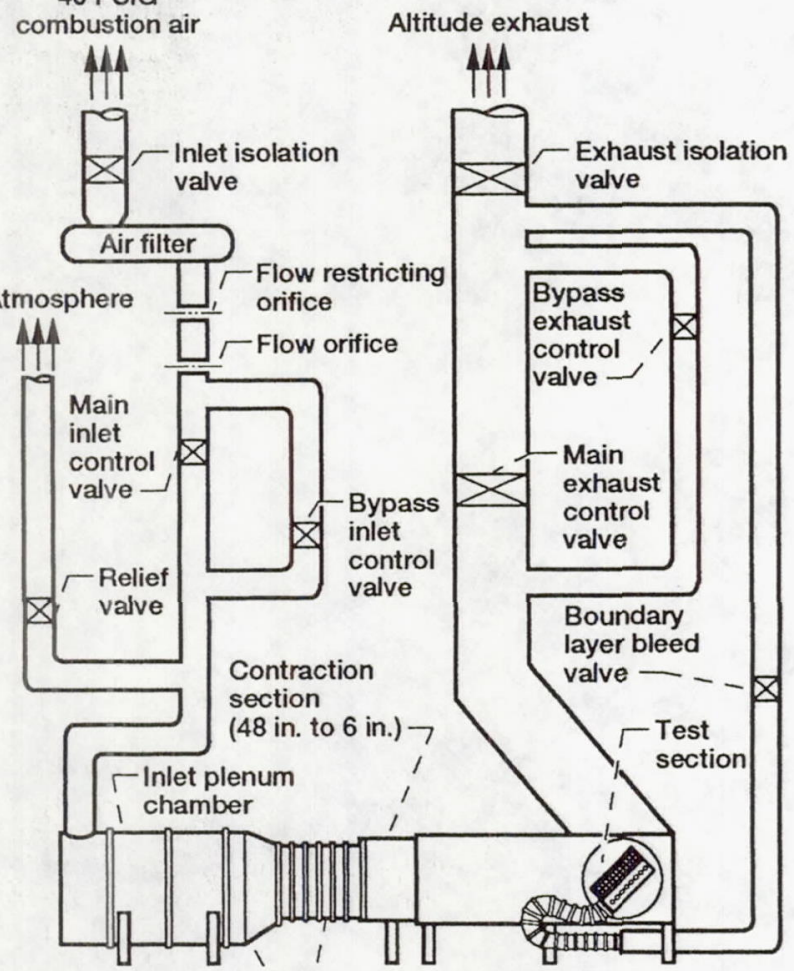

Transition section $\rightarrow$ L Flow conditioning section

Fig. 8. Transonic Turbine Blade Cascade air system schematic.

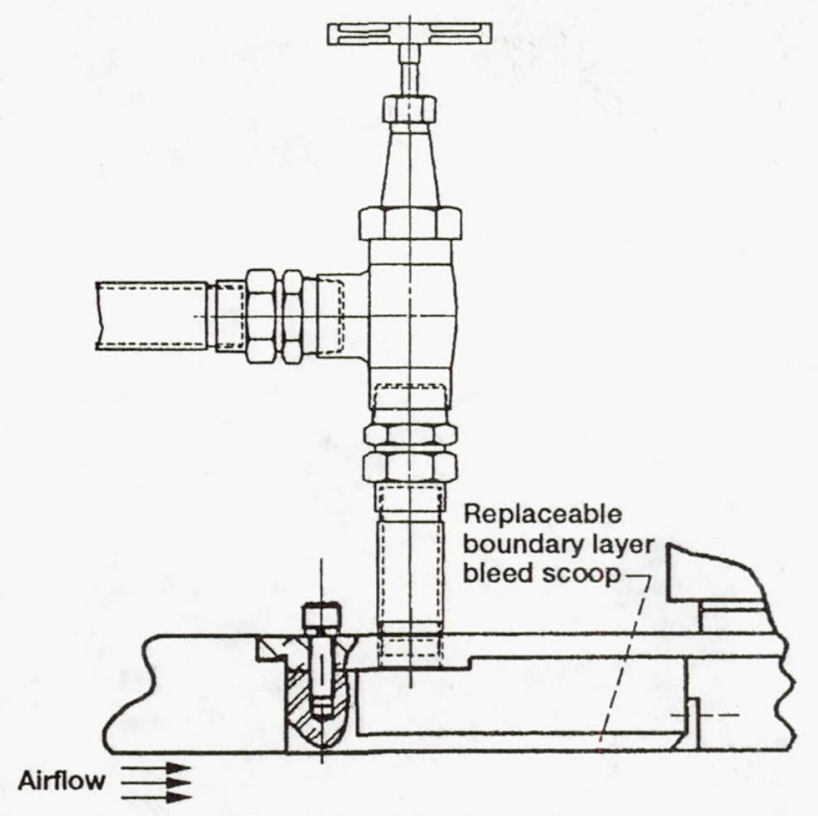

(a) Without boundary layer bleed.

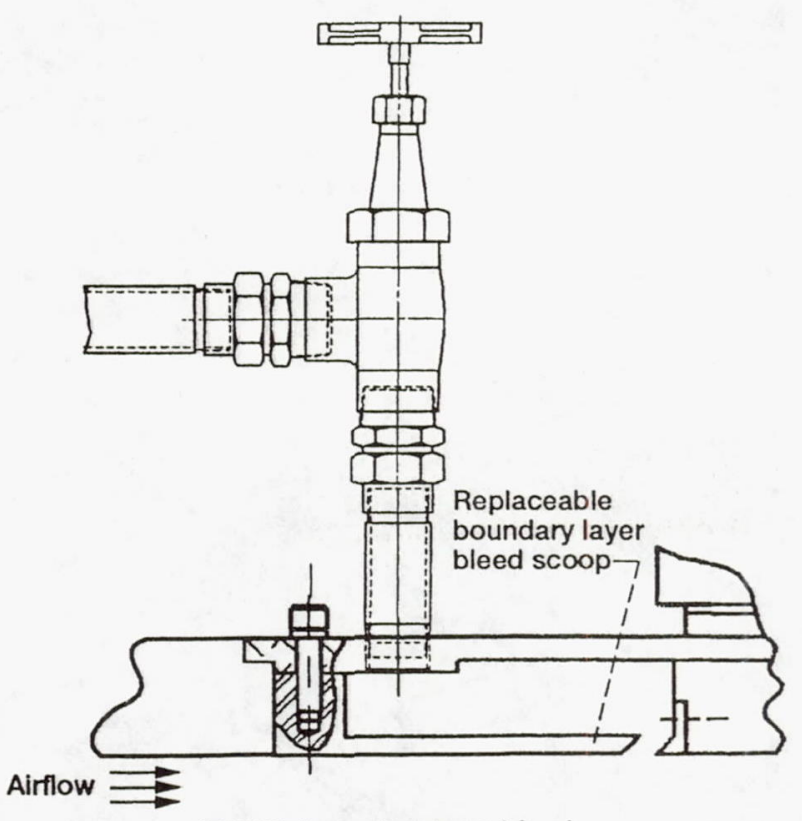

(b) With boundary layer bleed. 


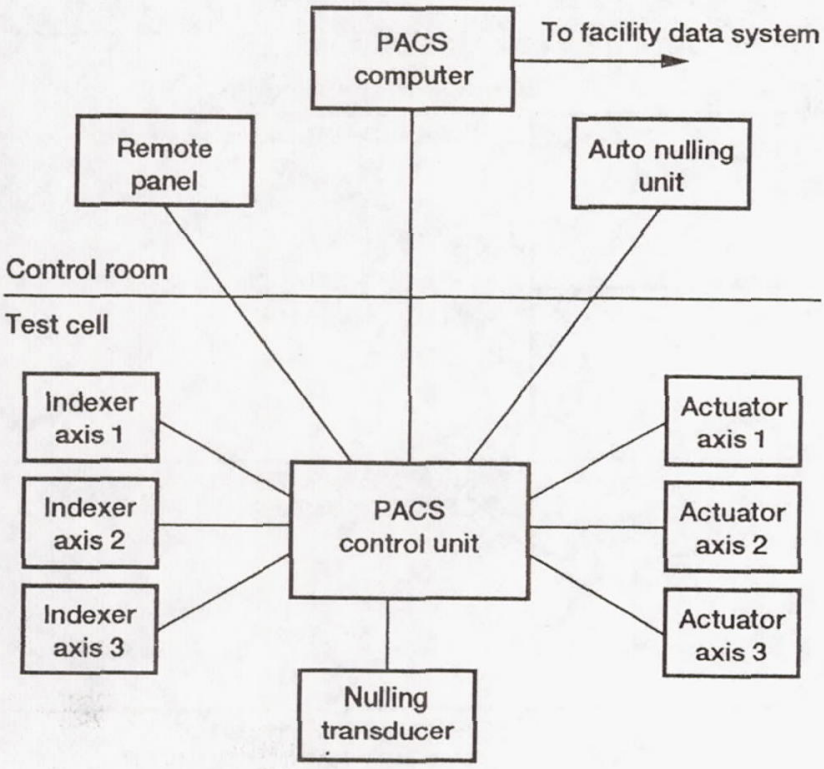

Fig. 10. Probe actuator control system.

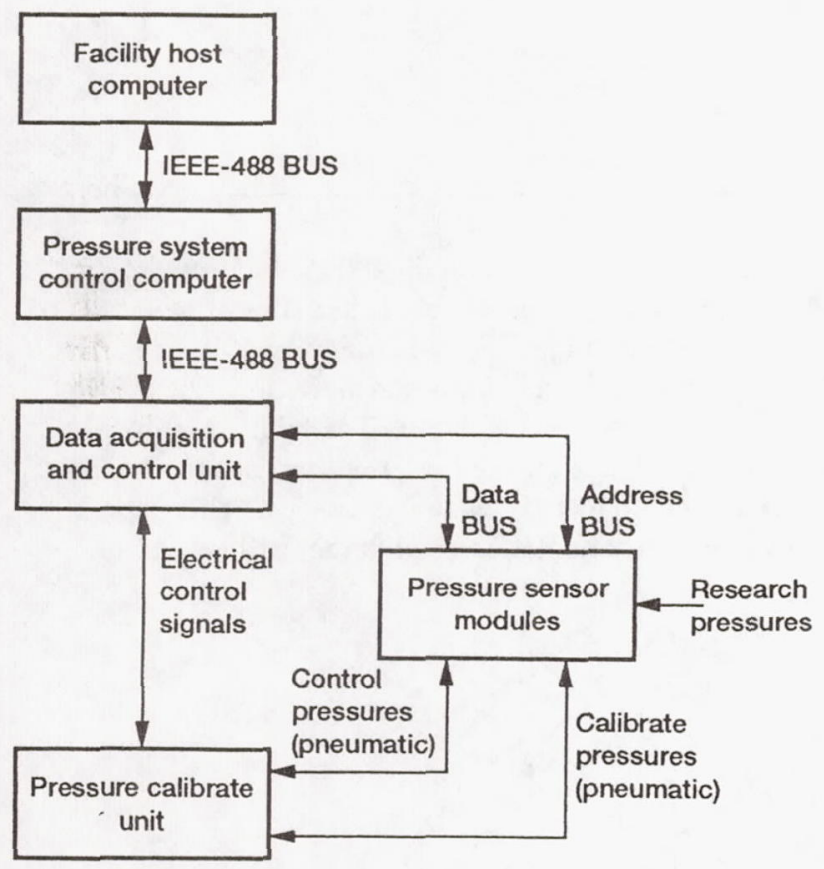

Fig. 11. Electronically scanned pressure system.

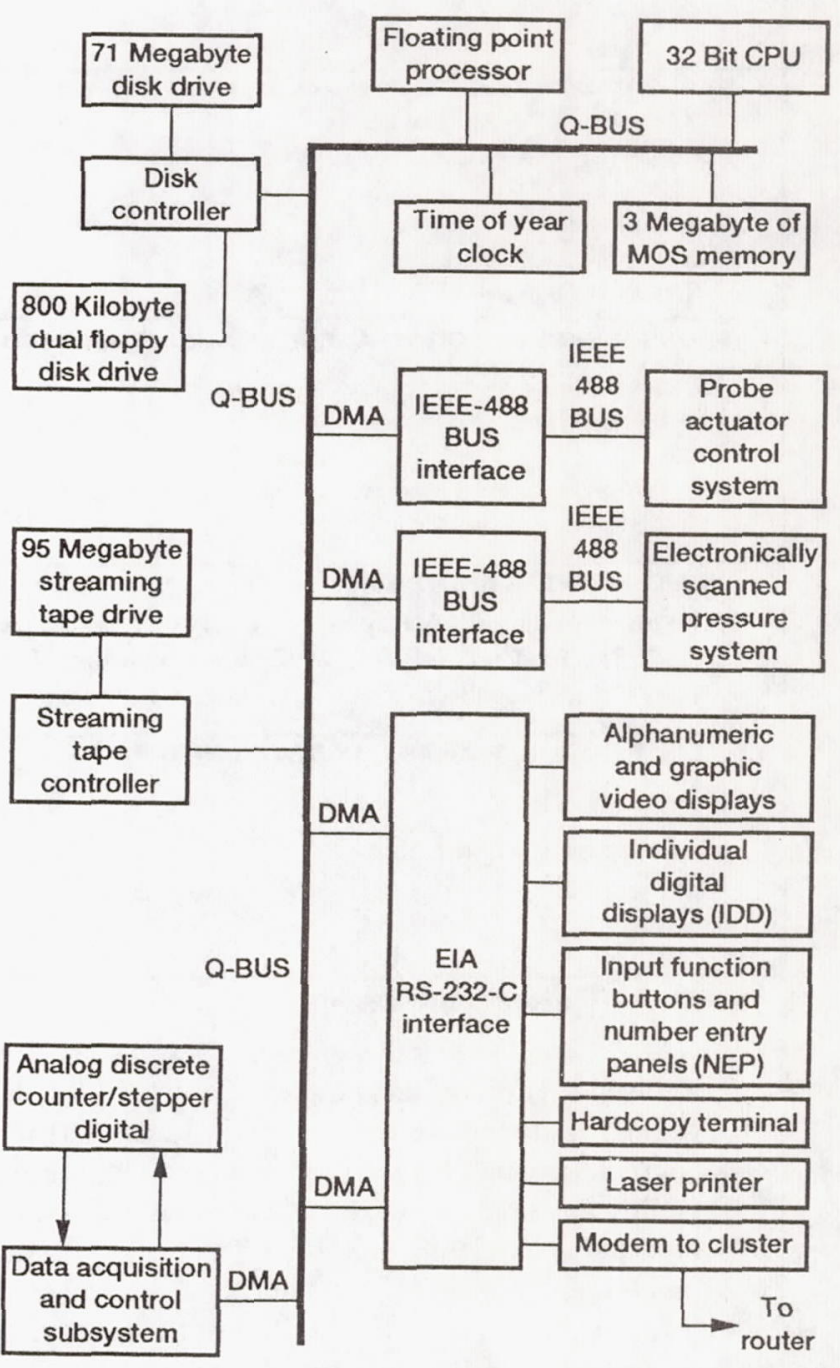

Fig. 12. Facility data acquisition system. 
Public reporting burden for this collection of information is estimated to average 1 hour per response, including the time for reviewing instructions, searching existing data sources, gathering and maintaining the data needed, and completing and reviewing the collection of information. Send comments regarding this burden estimate or any other aspect of this collection of information, including suggestions for reducing this burden, to Washington Headquarters Services, Directorate for information Operations and Reports, 1215 Jefferson Davis Highway, Suite 1204, Arlington, VA 22202-4302, and to the Office of Management and Budget, Paperwork Reduction Project (0704-0188), Washington, DC 20503.

\begin{tabular}{|l|c|c|}
\hline 1. AGENCY USE ONLY (Leave blank) & $\begin{array}{r}\text { 2. REPORT DATE } \\
1992\end{array}$ & $\begin{array}{r}\text { 3. REPORT TYPE AND DATES COVERED } \\
\text { Technical Memorandum }\end{array}$ \\
\hline
\end{tabular}

\section{TITLE AND SUBTITLE}

Transonic Turbine Blade Cascade Testing Facility

\section{6. $\operatorname{AUTHOR}(\mathrm{S})$}

Vincent G. Verhoff, William P. Camperchioli, and Isaac Lopez

\section{FUNDING NUMBERS}

WU-505-62-84

1L161102AH45

\section{PERFORMING ORGANIZATION} REPORT NUMBER

NASA Lewis Research Cente

Cleveland, Ohio 44135-3191

and

Propulsion Directorate

E-7002

U.S. Army Aviation Systems Command

Cleveland, Ohio 44135-3191

9. SPONSORING/MONITORING AGENCY NAMES(S) AND ADDRESS(ES)

National Aeronautics and Space Administration

Washington, D.C. 20546-0001

and

U.S. Army Aviation Systems Command

St. Louis, Mo. $63120-1798$

10. SPONSORING/MONITORING AGENCY REPORT NUMBER

NASA TM-105646

AVSCOM-TR-C-016

AIAA-92-4034

\section{SUPPLEMENTARY NOTES}

Prepared for the 17th Aerospace Ground Testing Conference sponsored by the American Institute of Aeronautics and Astronautics, Nashville, Tennesee, July 6-8, 1992. Vincent G. Verhoff, William P. Camperchioli, NASA Lewis Research Center, Cleveland, Ohio, and Isaac Lopez, Propulsion Directorate, U.S. Army Aviation System Command. Responsible person, Vincent G. Verhoff, (216) $433-5708$.

12a. DISTRIBUTION/AVAILABILITY STATEMENT

12b. DISTRIBUTION CODE

Unclassified - Unlimited

Subject Category 14

13. ABSTRACT (Maximum 200 words)

NASA Lewis Research Center has designed and constructed a new state-of-the-art test facility. This facility, the Transonic Turbine Blade Cascade, is used to evaluate the aerodynamics and heat transfer characteristics of blade geometries for future turbine applications. The facility's capabilities make it unique: no other facility of its kind can combine the high degree of airflow turning, infinitely adjustable incidence angle, and high transonic flow rates. The facility air supply and exhaust pressures are controllable to 16.5 psia and 2 psia, respectively. The inlet air temperatures are at ambient conditions. The facility is equipped with a programmable logic controller with a capacity of 128 input/output channels. The data acquisition system is capable of scanning up to 1750 channels per sec. This paper discusses in detail the capabilities of the facility, overall facility design, instrumentation used in the facility, and the data acquisition system. Actual research data is not discussed.

\section{SUBJECT TERMS}

Turbine cascade; Transonic cascade; Cascade linear cascade; Wind tunnel

15. NUMBER OF PAGES

12

16. PRICE CODE

$\mathrm{A03}$

\begin{tabular}{|c|c|}
\hline $\begin{array}{c}\text { 17. SECURITY CLASSIFICATION } \\
\text { OF REPORT }\end{array}$ & $\begin{array}{c}\text { 18. SECURITY CLASSIFICATION } \\
\text { OF THIS PAGE } \\
\text { Unclassified }\end{array}$
\end{tabular}

NSN 7540-01-280-5500
19. SECURITY CLASSIFICATION OF ABSTRACT Unclassified

\section{LIMITATION OF ABSTRACT}


National Aeronautics and

Space Administration

Lewis Research Center

Cleveland, Ohio 44135

Official Business

Penalty for Private Use $\$ 300$
FOURTH CLASS MAIL

ADDRESS CORRECTION REQUESTED
|||||

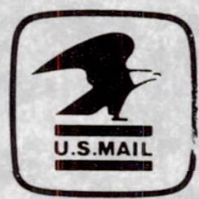

Postage and Fees Paid

Natıonal Aeronautics and

Space Administration

NASA 451 